Journal of Advanced College of Engineering and Management, Vol. 4, 2018

\title{
RURAL ROAD NETWORK DECISION MODEL FOR HILLY REGIONS OF NEPAL
}

\author{
Jagat Kumar Shrestha
}

Associate Professor, Department of Civil Engineering, Pulchowk Campus, IoE, T.U.

\begin{abstract}
Transportation cost is one of the major costs for public and private sectors in rural areas of developing countries (in order to deliver goods and services). This is due to the absence of links or to their poor physical conditions (such as road surface in a road network). To reduce the operation costs in existing links better road surfaces are needed. However, only some links can be improved or constructed to the best surface level at the same time, due to resource constraints. Hence, a careful decision about which links should be improved or constructed to achieve the minimum transportation cost is needed. This paper presents a decision support model for a rural road network that provides portfolio of suggested links for road network improvements or constructions and offers solutions for different budget levels minimizing the transportation cost in the rural road network. Mixed integer programming is used to get an optimal solution.
\end{abstract}

Keywords: rural road network, road surface, transportation cost, decision support model

\section{Introduction}

Nepal has the majority of the population concentrated in rural hill areas. The public facilities for the residents are also scattered in different villages in the hills. Many of the rural villages are not integrated in the national road network due to the absence of rural road network or poor condition of the existing roads. It is therefore difficult to get to public services and participate in economic and social activities resulting in low quality of life of the rural residents.

Only around $30 \%$ of Nepal is accessible by roads. More than $39 \%$ percent of the population in the hills is out of reach to all season roads within 4-hours walk (DoLIDAR, 2004). The road network is mostly developed in the plains region and only in few parts of the hilly regions. Moreover, there is a lack of development of the rural road network that covers the villages and public facilities in the rural hilly regions. Hence, there is a need to extend and develop these roads (particularly in the hilly regions of Nepal) in order to integrate the rural facilities and the rural residents in the national network.

All the villages and public facilities in rural areas cannot be connected by rural roads due to financial and technical constraints. However, nodal points in the planning region can be fixed in such a way that the rural settlements and public facilities can be covered maximum within a specified distance (Shrestha et al., 2012; Church and ReVelle, 1974). The development of rural road network with better surface level which connects all the nodal points may be an amicable solution for the hilly regions.

One of the typical problems in a developing country is scarcity of funds for rural infrastructure development. Apart from limited financial resources to build rural roads and public facilities, the lack of proper planning methodology of these rural infrastructures is also a major problem (Heng et al., 2006). Most of the models are developed based on the urban problems. The models developed for the urban areas may not be suitable for the rural areas.

In order to address the specific problem, a study on the planning of rural roads targeting optimized budget allocation is envisaged. This paper proposes rural road network decision model for solution of rural road network problem with different road surface options (e.g. earthen, gravel, and asphalt)considering the budget constraint for improvement of the road links to achieve minimum 
transportation cost.

This paper is organized as follows. Section 2 formulates the rural road network decision model. Section 3 deals with prioritization of rural road links. Section 4 presents the model application and validation with solution results. Finally, conclusions are provided in section 5.

\section{Rural roads network decision model}

In hilly regions of rural areas, the connection to the most important villages and facilities (nodal points) by road links can form the basic road network. The links in the network can be technically feasible new links, existing tracks, potential links or roads in poor condition (which can be upgraded to all-weather roads) and can be considered as candidate links for improvement with options of road surface (earthen, gravel, or asphalt). From all possible links connecting the nodal points in the region, a Minimum Spanning Tree (MST) can be obtained by using the Prim's Algorithm (Prim, 1957) to connect each nodal point in the network (Shrestha et al, 2012). The MST network can serve at a minimum connection level necessary for a rural accessibility to cover the settlements and public facilities. However, all the links in the MST network can not be constructed or upgraded in the same time mainly due to financial constraints. Hence, among the road links in the network, only some road links can be intervened. Then, selection of the road links to be intervened is necessary and this becomes a complex task to decision makers for taking a rational decision within a limited budget. In this situation, an appropriate decision support tool is needed to analyse the situations so that the decision made could be appropriate and justifiable. Hence, a decision support model is envisaged and formulated in this section as a decision support tool to address the rural road network problem in hilly regions of rural areas.

The network generally consists of existing road links which needs to be upgraded to a higher surface level. Few links can be new links and can be defined in constraints in case the new links are to be added to the existing network. The model sets a road surface to a link with option of earthen, gravel and asphalt so that transportation cost in the network is a minimum in that budget level.

A typical type of road network (backbone and branch) exists in hilly regions of Nepal (Shrestha, 2013). The backbone links are along the main ridges of hills and connects the branch links from the secondary ridges. The backbone links can be considered as important links. Hence, backbone links can also be defined in the model so that backbone links are upgraded before upgrading the branch links.

The rural road network decision modelsare formulated as follows. Residents are assumed on a number of village nodes (nodal points) of a given road network. The network is considered as an undirected graph $G=(N, L)$. Where, $N$ and $L$ are the sets of nodal points and road links respectively. The mathematical formulation considers the road surface with options for earthen, gravel, and asphalt.

The following notations are used. $S$ is the set of road surface options $S=(s 1, s 2, s 3)$ (for earthen, gravel, and asphalt respectively. $W_{i j}$ is the weightage to the link $(i, j) . C_{i j}^{S}$ is the travel cost per unit flow over surface type s on $\operatorname{link}(i, j) . d_{i j}$ is the distance from node $i$ to node $j . c_{i j}^{S}$ is the operating cost per unit flow of travelling over surface type s on $\operatorname{link}(i, j) . O_{i j}^{S}$ is the operating cost on link $(i, j)$ over surface type $S$, where $O_{i j}^{S}=d_{i j} . c_{i j}^{S} . B$ is an available investment budget, and $I_{i j}^{S}$ is the cost of improving link $(i, j)$ with surface type $s$.

The decision variables in this model are: $x_{i j}^{S}=1, x_{k l}^{S}=1$ if a link $(\mathrm{i}, \mathrm{j})$ is to be built with surface type $s, 0$ otherwise.

When the entire road links are to be in the single surface, the index s can be dropped out. 
The objective function is to minimise the operating costs in the network. The decisions are constrained by budgets and used to investigate different scenarios of decisions at different budget levels.

The model can be formed based on the Capacitated Facility Location/Network Design Problem (CFLNDP) (Melkote and Daskin, 2001) which seeks to minimize total transportation costs of the population subject to budget and spatial constraints can be reformulated as (Heng et al., 2007).

Minimise

$$
z=\sum_{S=1}^{3} \sum_{(i, j) \in L} C_{i j}^{S} x_{i j}^{S}
$$

The objective function of the model can be rewritten to consider the operating cost with weights to the links. Then, the equation (1) can be restated as follows:

Minimise

$$
z=\sum_{S=1}^{3} \sum_{(i, j) \in L, i<j} W_{i j} O_{i j}^{S} x_{i j}^{S}
$$

Subject to

$$
\begin{aligned}
& \sum_{S=1}^{3} \sum_{(i, j) \in L, i<j} I_{i j}^{S} x_{i j}^{S} \leq B \\
& \sum_{S=1}^{3} x_{i j}^{S}=1 \forall(\mathrm{i}, \mathrm{j}) \in \mathrm{L}, \quad \mathrm{i}<j \\
& \mathrm{x}_{\mathrm{ij}}^{\mathrm{S}} \in\{0,1\} \\
& \qquad \sum_{\mathrm{S}=1}^{3} \mathrm{x}_{\mathrm{ij}}^{\mathrm{S}} \leq \mathrm{x}_{\mathrm{kl}}^{\mathrm{S}} \forall(\mathrm{i}, \mathrm{j}) \in \mathrm{L},(\mathrm{k}, \mathrm{l}) \in \mathrm{L}, \mathrm{i}<j, k<l, j>m, m<l \\
& \mathrm{x}_{\mathrm{kl}}^{\mathrm{s}} \in\{0,1\} \forall(\mathrm{k}, \mathrm{l}) \in \mathrm{L}
\end{aligned}
$$

Equation (3) indicates that the improvement/construction expenditure is constrained to an investment budget. The construction expenditure term includes only one link either $(i, j)$ or $(j, i)$ on which both flows $j \rightarrow i$ and $i \rightarrow j$ can appear. Constraints (4) define that one link is to be paved with only one type of surface. These constraints also guarantee all links are to be connected with one of the surface options. If the network is entirely formed of new links the term $O_{i j}^{S}$ can be omitted. In initial stage, a new network road links may be developed with earthen surface only. 
When a rural road network consists of backbone links and the branch links or core network within a large network, the backbone links or core network are to be connected or upgraded before connecting or upgrading the other links. For this purpose, the branch or other links decision variables can be further defined as $x_{k l}$.

Here, the nodes which connect the backbone link are numbered before numbering the nodes that connects the secondary links. Where, $\mathrm{m}$ is the greatest node number in the backbone network. Hence, equation (6) assures that the secondary links cannot be selected unless all the backbone links in the network are selected. Equation (6) and equation (7) can be deleted where the backbone and branch network doesn't exist. Equation (5) and equation (7) has binary values.

\section{Prioritization of rural road links}

Fund available for rural road construction/upgrading is usually a constraint in a developing country. Hence, the available resources should be effectively used selecting the most potential links. For this, a suitable prioritisation method is necessary. There are different prioritisation procedures for road networks for rural areas. However, these procedures have some practical limitations to use in rural road network.

Most of the prioritisation methods for road links are usually based on economic returns from the road linkages. The traditional feasibility indicators for economic evaluation of highway are Net Present Value (NPV), discounted benefit cost $(\mathrm{B} / \mathrm{C})$ ratio, and internal rate of return (IRR). These conventional methods are used for urban, and highways and higher standard roads where the economic return can be fairly estimated. Basically, traffic on the roads is the main parameter for evaluating the economic viability of roads. However, in rural areas, the traffic volume is usually low and there is rarely significant economic activity. The traffic in rural roads in hilly regions may be lower than 25 vehicles per day (Airey\& Taylor, 1999). The conventional economic indicator may not be suitable for rural roads particularly for hilly regions. There is significant difficulty in quantifying the economic benefits and return from the rural roads. However, from a social point of view, the rural villages and rural facilities should be connected or covered for the accessibility of goods and services to be at least to a minimum level. Hence, a different and simple approach is necessary to prioritise the road links in a rural road network. The following sub-sections have explored four such methods that can be applicable to prioritise the rural road links in a network.

\subsection{Population served by link}

The key social factor in the rural areas is the population covered by a road link. Population can be considered a good proxy for traffic in rural areas because traffic data generally is difficult to get. Here, the role of other factors may not be significant. Hence, the construction standards for a link can be fixed on the basis of the population served by the link (Kumar \& Kumar, 1999).Cost is justified if the link covers more population. Hence, calculation of priority factor based on the population covered by links can be a realistic approach. The weightage assigned based on population can be as comparable as trip generation in a link. The link which serves the more population can be considered as a potential link in the rural areas. Therefore, population served by the link can be considered as an important indicator for the rural road links prioritisation. The criteria can be the most simple and the population data is easily available.

\subsection{Population served by link}

The construction/improvement cost can be other criteria for the evaluation and prioritisation of rural roads and the cost should be justifiable in terms of benefits. However, there is a difficulty to quantify benefits from road in rural areas. The benefit from the road links can be considered taking cost of 
intervention with population, the population served with unit investment for prioritisation of rural roads(Kumar \& Kumar, 1999) as simple parameter. The accessibility to the rural people can be considered as benefit of the investment in rural roads. Thus, the ratio of population served by a link and its construction cost can be taken as good proxy for the expected benefit from a rural road link. The link serving higher population per unit investment receives high priority. The priority for a rural road link can be calculated as follows:

Priority for a road link = Population served by the link/construction cost of the link.

The link lengths can be taken as a good proxy for construction costs(Kumar and Tillotson, 1985). The construction costs can be taken as proportional to the lengths of links. Hence, the equation (8) can be rewritten as population served per unit length of a link in $\mathrm{km}$ (population served/km). Similar type of parameter (population per unit cost) is adopted in DoLIDAR (2012).

\subsection{Person-km}

Travel costs due to absence of a link can also be considered as a factor in the evaluation of rural road network for the population of the rural areas. The travel cost can be more than the construction cost of a rural road link. However, it is difficult to quantify travel costs and it is a time consuming work. A huge amount of travel data is needed to model the travel behaviour of the rural settlements, which is not practical. However, the effect of travel cost can be included in the evaluation of rural road linkages. The travel cost is related to the distance from road head (point up to where road reached) to a village and the population in the village. The higher the population, the greater is the travel cost. Similarly, the greater the distance from village to the road head, the greater will be the travel cost. The factor, person-km (multiplication of population and the distance travelled), is proportional to the total travel costs. Indirectly, this factor can be used to take the effect of travel cost in the evaluation of rural road linkages. (Kumar \& Tillotson, 1985; Makarchi \& Tillotson, 1991; Singh, 2010). The methodology can be applied when only the population of the villages and linear distance between them are known. This is an advantage for rural areas where this simple data is often all that is available. DoLIDAR (2012) has also taken the parameter (population-distance) in a different form (population-hour) based on walking time to a road corridor.

\subsection{Gravity model}

The gravity model has been widely used to predict flows. The simplest gravity flow formulation (MacKinnon \& Hudgson, 1969) is:

$F_{i j}=k \frac{P_{i} P_{j}}{D_{i j}{ }^{b}}$

Where, $i$ and $j$ are the nodal points, $F_{i j}$ is traffic flow through link $i j . P_{i}$ and $P_{j}$ are the populations at node $i$ and node $j . D_{i j}$ is the distance between node $i$ and node $j$. For obtaining the data, population can be taken from census data, while the distance between population centres can be obtained from map measurement.

However, the main difficulty is the estimation of proportionality parameter $(\mathrm{k})$ and exponent of distance (b) in equation (9), the value of b is assumed as 2 in some studies (Jung et al, 2008, Shrestha, 2003) and $\mathrm{k}$ can be taken as constant. The model can also be used in traffic flow estimation between two nodal points in a rural road network. 


\subsection{Selection of parameters}

For the rural areas, particularly for hilly regions, prioritisation based on simple parameter may be enough and practical. These methods can be any of the population covered by a road link, person$\mathrm{km}$, population per unit construction cost, and use of gravity flow model. However, the population covered by a link would be the simplest one and fair enough. The network links can also be prioritised based on all the parameters and can be superposed to compare the results. The most convincing parameters can be taken as weightage for further analysis of the network. The combination of parameters (with factors) can also be made to incorporate the effect of desired parameters.

When the traffic data and other data can be collected or is readily available, the weighting of links can be determined accordingly. The direct benefit methods can be used for the developed areas using the $\mathrm{NPV}, \mathrm{IRR}$, and $\mathrm{B} / \mathrm{C}$ ratio indicators for appraising the rural road networks.

\section{Models application and validation}

The applicability of the proposed model is tested in the real rural roads network of previous 15 VDC(Shrestha et al, 2012 )in the hilly region in Gorkha district of Nepal as shown in Figure 1.

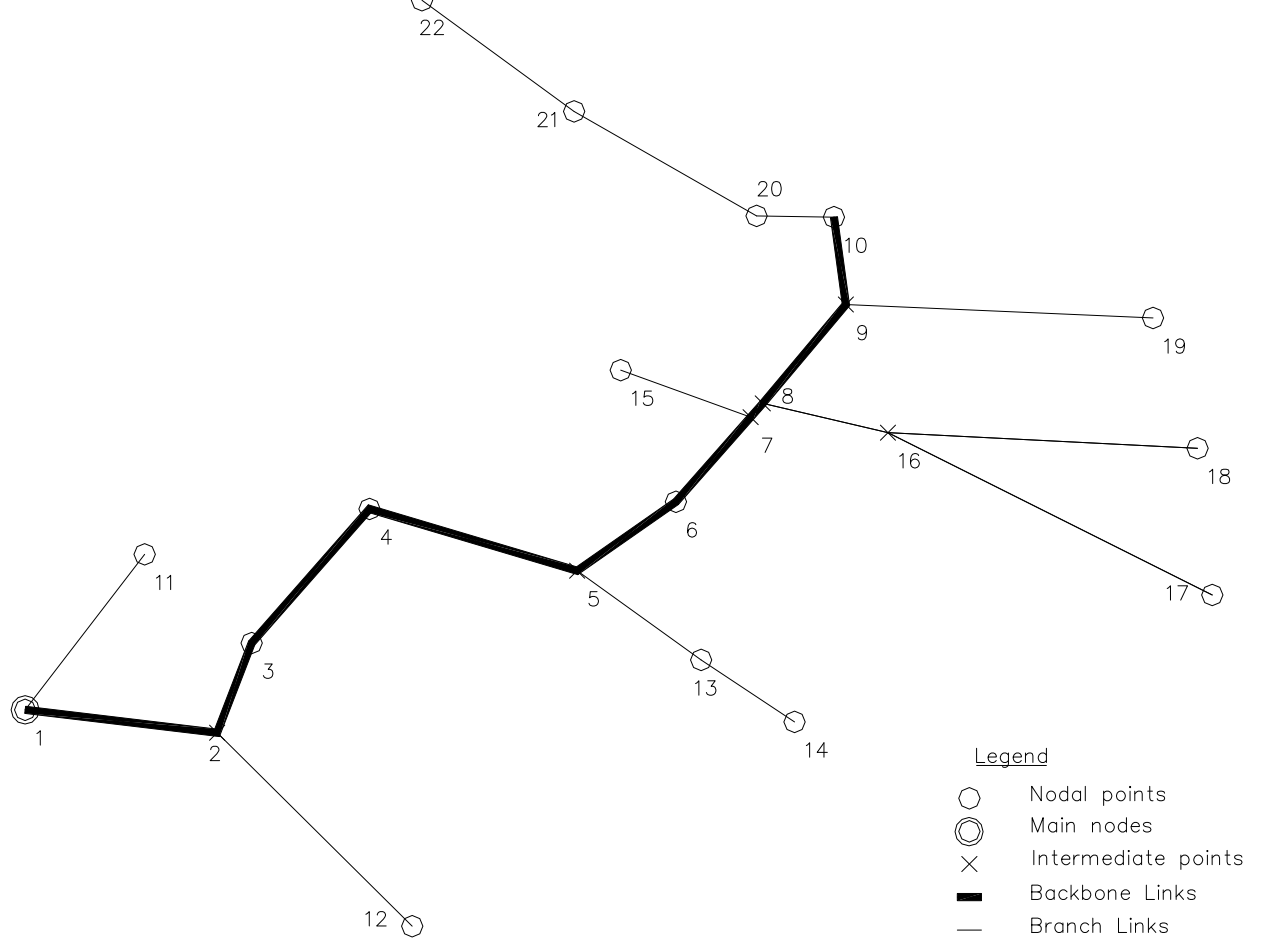

Fig.1: Test rural road network for model application

The network shown in Fig. 1 is the MST of the rural road network defined based on covering based approach (Shrestha et al, 2012) for the minimum level of connectivity necessary for the region. The network has backbone links (bold links) connecting nodes from node 1 to node 10 .

Weightage of links of the test network has been calculated for each parameter (Population served by links (P1),Person-km (P2), Population served/km (P3), and Gravity flow model (P4)) as discussed in the previous section.

The weight calculated for each link is presented in Table 1. Total population served by each road link is shown in the third column. Similarly, person- $\mathrm{km}$ (total) is in column four, population served $/ \mathrm{km}$ in 
column five and traffic flow calculated in the link assuming b as 2 in column six has been presented. Accordingly, weightage of each link is calculated based on the total population in the region for P1, $\mathrm{P} 3$, and $\mathrm{P} 4$. For $\mathrm{P} 2$, the total person-km is used to calculate the weightage. The weightage calculated for P1, P2, P3, and P4 are respectively shown in column seven, eight, nine, and ten.

Table 1: Weight based on population, person-km, population per unit construction cost and gravity flow model

\begin{tabular}{|c|c|c|c|c|c|c|c|c|c|}
\hline \multirow{2}{*}{ Links } & \multirow{2}{*}{$\begin{array}{l}\text { length } \\
(\mathrm{km})\end{array}$} & \multirow{2}{*}{$\begin{array}{l}\text { Population } \\
\text { served (P1) }\end{array}$} & \multirow{2}{*}{$\begin{array}{l}\text { Person-km } \\
\quad(\mathrm{P} 2)\end{array}$} & \multirow{2}{*}{$\begin{array}{l}\text { Population } \\
\text { served/km } \\
\text { (P3) }\end{array}$} & \multirow{2}{*}{$\begin{array}{l}\text { Traffic } \\
\text { flow x k } \\
\text { (P4) }\end{array}$} & \multicolumn{4}{|c|}{ Weightage for } \\
\hline & & & & & & P1 & $\mathrm{P} 2$ & P3 & P4 \\
\hline $1-2$ & 3.52 & 58936 & 1364905 & 16743 & 6784469 & 92.9 & 100.0 & 43.2 & 0.0 \\
\hline $1-11$ & 5.75 & 4501 & 25881 & 783 & 3509997 & 7.1 & 1.9 & 2.0 & 51.7 \\
\hline $2-3$ & 3.34 & 51458 & 1112582 & 15407 & 4657089 & 81.1 & 81.5 & 39.8 & 68.6 \\
\hline $2-12$ & 6.00 & 7478 & 44868 & 1246 & 2127380 & 11.8 & 3.3 & 3.2 & 31.4 \\
\hline $3-4$ & 3.44 & 48021 & 940712 & 13960 & 1856578 & 75.7 & 68.9 & 36.0 & 27.4 \\
\hline $4-5$ & 5.70 & 43029 & 775520 & 7549 & 957603 & 67.8 & 56.8 & 19.5 & 14.1 \\
\hline $5-6$ & 4.12 & 33766 & 482729 & 8196 & 512915 & 53.2 & 35.4 & 21.2 & 7.6 \\
\hline $5-13$ & 2.69 & 9263 & 47526 & 3443 & 275158 & 14.6 & 3.5 & 8.9 & 4.1 \\
\hline $6-7$ & 2.49 & 31520 & 343613 & 12659 & 996213 & 49.7 & 25.2 & 32.7 & 14.7 \\
\hline $7-8$ & 0.70 & 27112 & 257458 & 38731 & 442900 & 42.7 & 18.9 & 100.0 & 6.5 \\
\hline $7-15$ & 1.74 & 4408 & 7670 & 2533 & 553313 & 7.0 & 0.6 & 6.5 & 8.2 \\
\hline $8-9$ & 2.78 & 18144 & 157578 & 6527 & 307724 & 28.6 & 11.5 & 16.9 & 4.5 \\
\hline $8-16$ & 1.50 & 8968 & 80902 & 5979 & 135176 & 14.1 & 5.9 & 15.4 & 2.0 \\
\hline $9-10$ & 2.10 & 12679 & 76697 & 6038 & 215554 & 20.0 & 5.6 & 15.6 & 3.2 \\
\hline $9-19$ & 5.57 & 5465 & 30440 & 981 & 92170 & 8.6 & 2.2 & 2.5 & 1.4 \\
\hline $10-20$ & 1.20 & 10257 & 50071 & 8548 & 5695718 & 16.2 & 3.7 & 22.1 & 84.0 \\
\hline $13-14$ & 4.20 & 5383 & 22609 & 1282 & 1184016 & 8.5 & 1.7 & 3.3 & 17.5 \\
\hline $16-17$ & 7.73 & 4040 & 67450 & 523 & 58823 & 6.4 & 4.9 & 1.4 & 0.9 \\
\hline $16-18$ & 7.35 & 4928 & 36221 & 670 & 76353 & 7.8 & 2.7 & 1.7 & 1.1 \\
\hline $20-21$ & 3.28 & 7236 & 37763 & 2206 & 1379806 & 11.4 & 2.8 & 5.7 & 0.3 \\
\hline $21-22$ & 5.12 & 2740 & 14029 & 535 & 469934 & 4.3 & 1.0 & 1.4 & 6.9 \\
\hline
\end{tabular}


Operating cost per unit flow over earthen, gravel, and asphalt surface are taken NRs 50.64, NRs 45.64, and NRs 36.79 (Tech Studio, 2011).(NRs is Nepalese Rupees, 1 Euro $\approx$ NRs 110)

The mathematical models were solved using MPL for Windows 4.2 as the modelling language with CPLEX 10.0's Mixed Integer Programming solver. An intervention decision analysis is conducted in different budget levels.

As the result, the suggested intervention in the network link at the budget levelsNRs 100 millions to NRs 800 millions in the interval of 100 millions based on prioritisation methods P1 (population served by link), P2 (person-km), P3 (population served/km), and P4 (Gravity flow model)are respectively presented in Table 2-5 and in Fig. 2.The model suggests different road surface level for different links. As per the availability of the budget, the decision maker can select a set of links for intervention from these tables based on a prioritisation method (P1, P2, P3, and P4) respectively according to the rural road network decision model.

Table 2: The intervention in the network link at different level of budget based on P1

\begin{tabular}{|c|c|c|c|c|c|c|c|c|}
\hline \multirow{2}{*}{ Links } & \multicolumn{7}{|c|}{ Budget (NRs) in millions } \\
\cline { 2 - 10 } & 100 & 200 & 300 & 400 & 500 & 600 & 700 & 800 \\
\hline $1-2$ & & A & A & A & A & A & A & A \\
\hline $2-3$ & A & A & A & A & A & A & A & A \\
\hline $3-4$ & A & A & A & A & A & A & A & A \\
\hline $4-5$ & & A & A & A & A & A & A & A \\
\hline $5-6$ & & A & A & A & A & A & A & A \\
\hline $6-7$ & A & A & A & A & A & A & A & A \\
\hline $7-8$ & A & A & A & A & A & A & A & A \\
\hline $8-9$ & & & A & A & A & A & A & A \\
\hline $9-10$ & & & G & A & A & A & A & A \\
\hline $1-11$ & & & & & & & A & A \\
\hline $2-12$ & & & & & A & A & A & A \\
\hline $5-13$ & & & & A & A & A & A & A \\
\hline $13-14$ & & & & & A & A & A & A \\
\hline $7-15$ & & & & A & A & A & A & A \\
\hline $8-16$ & & & G & A & A & A & A & A \\
\hline $16-17$ & & & & & & & & A \\
\hline $16-18$ & & & & & & G & A & A \\
\hline $9-19$ & & & & & & A & A & A \\
\hline $10-20$ & & & A & A & A & A & A & A \\
\hline $20-21$ & & & & A & A & A & A & A \\
\hline $21-22$ & & & & & & & & G \\
\hline
\end{tabular}


Table 3: The intervention in the network link at different level of budget based on P2

\begin{tabular}{|c|c|c|c|c|c|c|c|c|}
\hline & \multicolumn{8}{|c|}{ Budget (NRs) in millions } \\
\hline Links & 100 & 200 & 300 & 400 & 500 & 600 & 700 & 800 \\
\hline $1-2$ & A & A & A & A & A & A & A & A \\
\hline $2-3$ & A & A & A & $\mathrm{A}$ & $\mathrm{A}$ & A & $\mathrm{A}$ & A \\
\hline $3-4$ & G & A & A & $\mathrm{A}$ & A & A & $\mathrm{A}$ & $\mathrm{A}$ \\
\hline $4-5$ & & A & A & A & A & A & A & A \\
\hline $5-6$ & & A & A & A & A & A & A & A \\
\hline $6-7$ & & A & A & $\mathrm{A}$ & $\mathrm{A}$ & A & A & A \\
\hline $7-8$ & A & A & A & A & A & A & A & A \\
\hline $8-9$ & & & A & $\mathrm{A}$ & A & A & $\mathrm{A}$ & A \\
\hline $9-10$ & & & G & A & A & A & A & A \\
\hline $1-11$ & & & & & & & & A \\
\hline $2-12$ & & & & & & A & A & A \\
\hline $5-13$ & & & & A & A & A & A & A \\
\hline $13-14$ & & & & G & A & G & $\mathrm{A}$ & $\mathrm{A}$ \\
\hline $7-15$ & & & & & & $\mathrm{G}$ & $\mathrm{G}$ & \\
\hline $8-16$ & & & A & $\mathrm{A}$ & A & A & $\mathrm{A}$ & A \\
\hline $16-17$ & & & & & A & A & $\mathrm{A}$ & A \\
\hline $16-18$ & & & & & & & A & A \\
\hline $9-19$ & & & & & & A & A & A \\
\hline $10-20$ & & & G & A & A & A & A & A \\
\hline $20-21$ & & & & A & A & A & A & A \\
\hline $21-22$ & & & & & & & & A \\
\hline
\end{tabular}


Table 4: The intervention in the network link at different level of budget based on P3

\begin{tabular}{|c|c|c|c|c|c|c|c|c|}
\hline & \multicolumn{8}{|c|}{ Budget (NRs) in millions } \\
\hline Links & 100 & 200 & 300 & 400 & 500 & 600 & 700 & 800 \\
\hline $1-2$ & & A & A & A & A & A & A & A \\
\hline $2-3$ & $\mathrm{~A}$ & A & A & $\mathrm{A}$ & $\mathrm{A}$ & A & A & A \\
\hline $3-4$ & A & A & A & A & A & A & A & $\mathrm{A}$ \\
\hline $4-5$ & & & G & A & A & A & A & A \\
\hline $5-6$ & & & A & A & A & A & A & A \\
\hline $6-7$ & A & A & A & $\mathrm{A}$ & A & A & A & A \\
\hline $7-8$ & A & A & A & A & A & A & A & A \\
\hline $8-9$ & & A & A & A & A & A & A & A \\
\hline $9-10$ & & A & A & $\mathrm{A}$ & A & A & A & A \\
\hline $1-11$ & & & & & & $\mathrm{G}$ & $\mathrm{A}$ & A \\
\hline $2-12$ & & & & & $\mathrm{~A}$ & $\mathrm{~A}$ & A & A \\
\hline $5-13$ & & & & A & A & A & A & A \\
\hline $13-14$ & & & & & A & A & A & A \\
\hline $7-15$ & & & G & A & A & A & A & A \\
\hline $8-16$ & & A & A & A & A & A & A & A \\
\hline $16-17$ & & & & & & & & $\mathrm{G}$ \\
\hline $16-18$ & & & & & & & $\mathrm{G}$ & A \\
\hline $9-19$ & & & & & & A & A & A \\
\hline $10-20$ & & A & A & A & A & A & A & A \\
\hline $20-21$ & & & & A & A & A & A & A \\
\hline $21-22$ & & & & & & & A & A \\
\hline
\end{tabular}


Table 5: The intervention in the network link at different level of budget based on P4

\begin{tabular}{|c|c|c|c|c|c|c|c|c|}
\hline & \multicolumn{8}{|c|}{ Budget (NRs) in millions } \\
\hline Links & 100 & 200 & 300 & 400 & 500 & 600 & 700 & 800 \\
\hline $1-2$ & A & A & A & A & A & A & A & A \\
\hline $2-3$ & $\mathrm{~A}$ & A & A & $\mathrm{A}$ & $\mathrm{A}$ & A & A & A \\
\hline $3-4$ & & G & A & A & A & A & A & $\mathrm{A}$ \\
\hline $4-5$ & & G & G & G & A & A & A & A \\
\hline $5-6$ & & G & G & G & A & A & A & A \\
\hline $6-7$ & A & G & A & $\mathrm{A}$ & A & A & A & A \\
\hline $7-8$ & G & A & A & A & A & A & A & A \\
\hline $8-9$ & & G & G & G & A & A & A & A \\
\hline $9-10$ & & G & G & $\mathrm{G}$ & $\mathrm{G}$ & A & A & A \\
\hline $1-11$ & & & A & A & A & A & $\mathrm{A}$ & A \\
\hline $2-12$ & & & & A & $\mathrm{A}$ & $\mathrm{A}$ & A & A \\
\hline $5-13$ & & & & & & A & A & A \\
\hline $13-14$ & & & & & A & A & $\mathrm{A}$ & A \\
\hline $7-15$ & & & A & A & A & A & A & A \\
\hline $8-16$ & & & & $\mathrm{G}$ & & $\mathrm{G}$ & A & A \\
\hline $16-17$ & & & & & & & & $\mathrm{G}$ \\
\hline $16-18$ & & & & & & & $\mathrm{G}$ & A \\
\hline $9-19$ & & & & & & & A & A \\
\hline $10-20$ & & A & A & A & A & A & A & A \\
\hline $20-21$ & & & & A & A & A & A & A \\
\hline $21-22$ & & & & & & A & A & A \\
\hline
\end{tabular}


The suggested links with road surface is shown in Fig. 2 for the budget level NRs 400 millions and Fig. 3 for the budget level NRs 600 millions. It can be seen that the model has selected the backbone links (from node 1 to node 10) first and branch links afterwards.

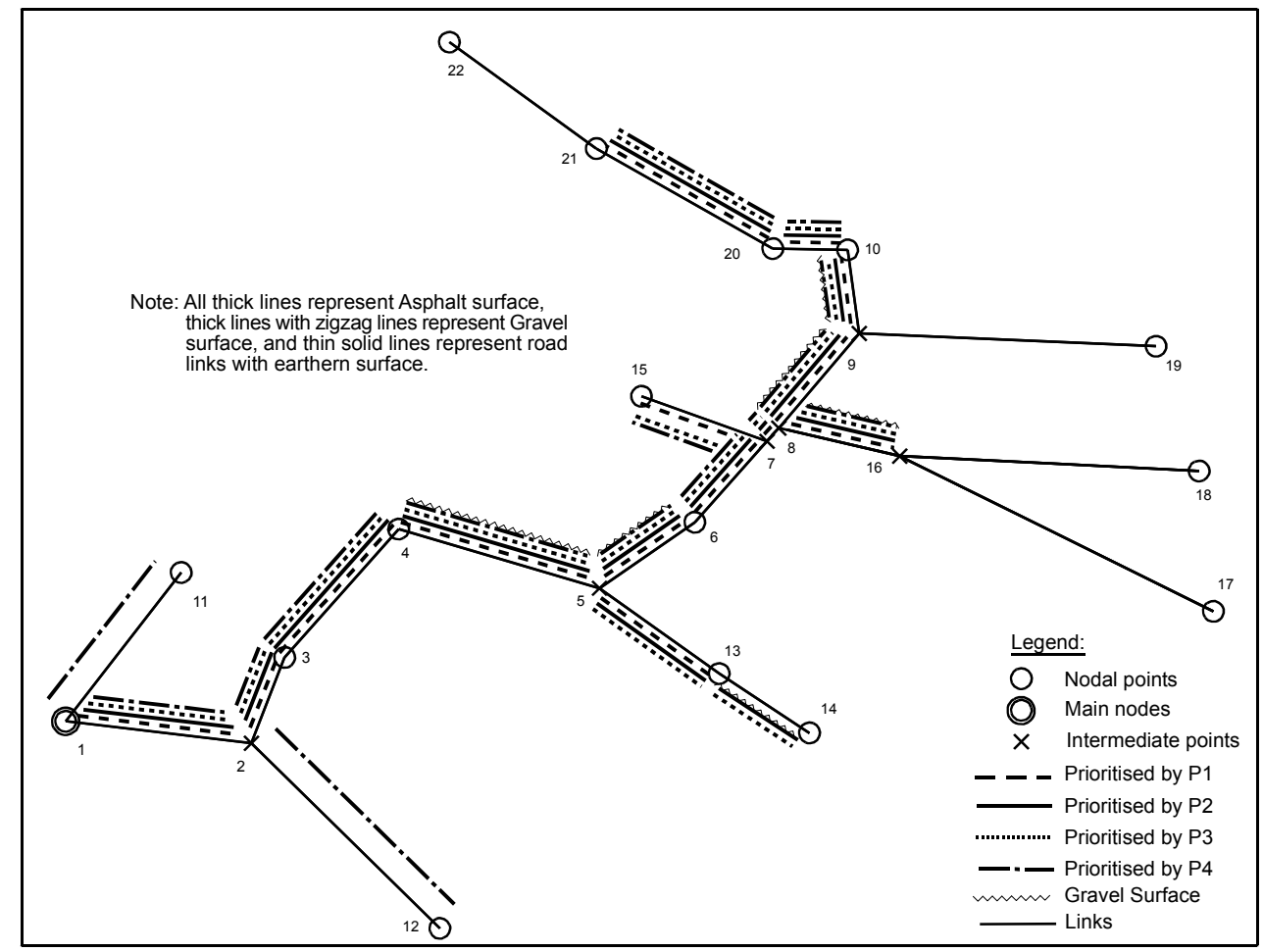

Fig 2: An optimal network intervention for a budget of NRs 400 million

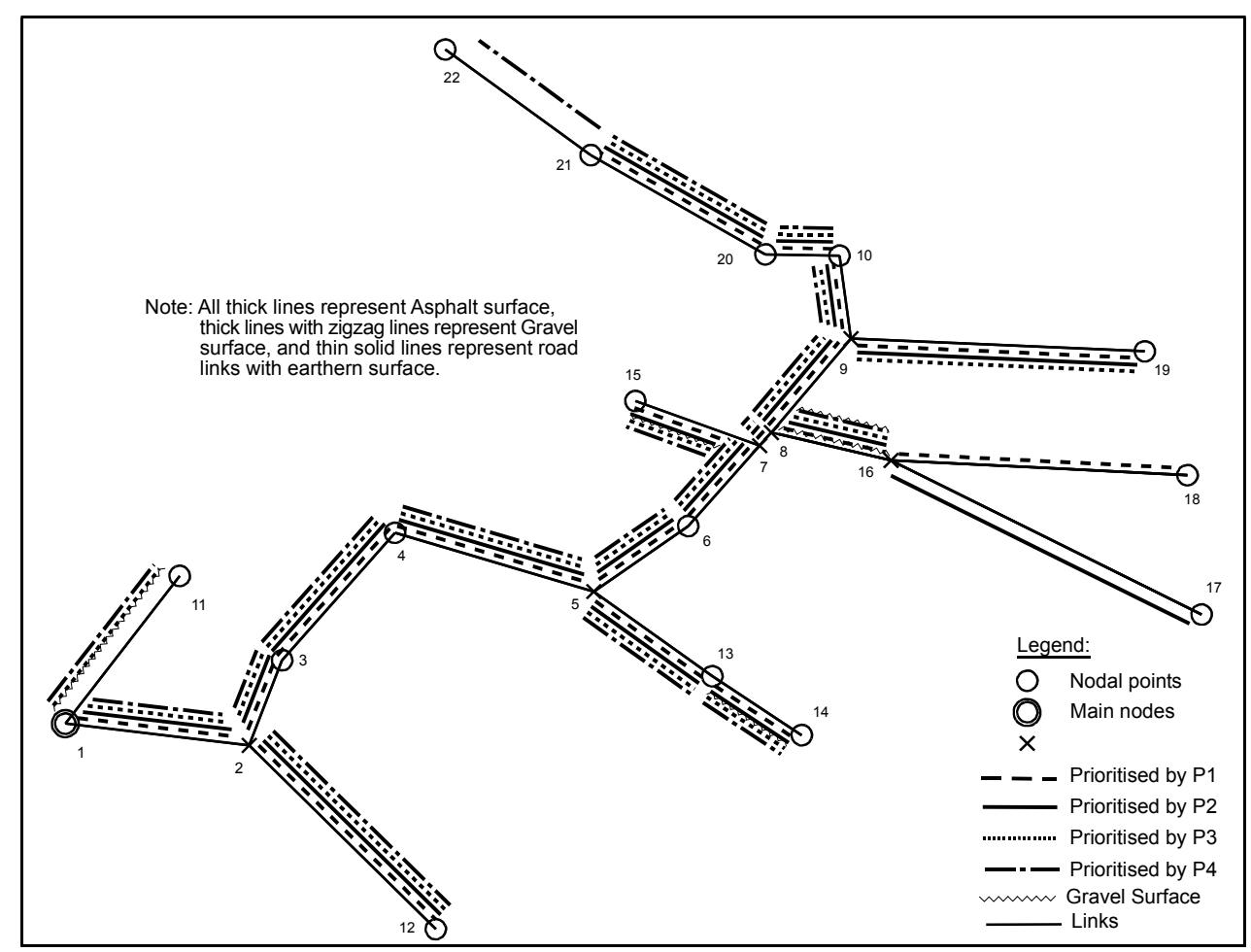

Fig 3: An optimal network intervention for a budget of NRs 600 million 
The implementation of the proposed model in rural road network problem in the 15 VDCs of Gorkha district shows that the decision model can be used to analyse decision scenarios in different budget levels with the prioritisation procedures. It can be a practical and simple basis for the solution of rural roads network decision problems in rural areas, particularly in the hilly region of Nepal.

\section{Conclusions}

In this paper, it was studied the solution of rural road network decision problem to provide better accessibility to settlements and public services in hilly regions around the road network along with cost-effective road improvements. A model is proposed as a solution of the problem and tested in a real road network. The model provided portfolios of suggested links for road network improvements, and offered solutions for different budget levels optimizing the transportation cost in the rural road network with different types of road surface (earthen, gravel, or asphalt). This shows that the proposed decision model can be a practical and realistic decision support tool for the study and development of road networks in rural areas, particularly inhilly regions of developing countries like Nepal. 


\section{References}

1. Airey, T. Taylor; G. (1999). "Prioritization Procedure for Improvement of Very Low-Volume Roads", Transportation Research Board of the National Academies 1652.

2. Church, R. L., ReVelle, C.(1974). "The maximal covering location problem”, Papers of the Regional Science Association 32: 101-118.

3. DoLIDAR (2004). "Local Infrastructure Development Policy", Ministry of Local Development, Government of Nepal, Kathmandu.

4. DoLIDAR (2012). "Approach for the Development of Agricultural and Rural Roads: A Manual for the Preparation of District Transport Master Plan and for the Implementation of Rural Road Sub-projects," Ministry of Local Development, Government of Nepal, Kathmandu.

5. Heng, S.; Hirobata, Y.; Nakanishi, H. (2006). "An integrated model of rural road network design and multi public facility locations in developing countries", Conference on Infrastructure Planning Committee, Japan Society of Civil Engineers Vol.34.

6. Heng, S.; Hirobata, Y.; Nakanishi, H. (2007). "An Integrated Model of Rural Infrastructure Design in Developing Countries", Proceedings of the Eastern Society for Transportation Studies.

7. Jung, W. S., Fengzhong, W., Stanley H. E. (2008). "Gravity model in the Korean highway". EPL (Europhysics Letters), Volume 81: 4

8. Kumar, A., Kumar, P. (1999). "User friendly model for planning rural road." Transportation research record, 1652, 31-39.

9. Kumar, A., Tilloston, H.T. (1985). "A planning model for rural roads in India." Proc., Seminar on roads and road transport in rural areas, Central Road Research Institute, New Delhi, India, 13-19.

10. MacKninnon, R.D., Hudgson, M.J. (1969). "The highway system of South-western Ontario and Quebec: some simple network generation models". Urban environment study, University of Toronto.

11. Makarachi, A. K, Tillotson, H.T. (1991). "Road planning in rural areas of developing countries." Europian Journal of Operational Research, 53, 279-287.

12. Melkote, S.; Daskin, M.S. (2001). "An integrated model of facility location and transportation network design", Transportation Research Part A, Vol. 35, 515-538.

13. Prim, R. C. (1957). "Shortest connection networks and some generalizations", Bell System Technical Journal, 36: 1389-1401.

14. Shrestha, C. B. (2003). "Developing a computer-aided methodology for district road network planning and prioritization in Nepal", International Journal of Transport Management Volume 1, 3: 157-174

15. Shrestha, J. K. (2013). "Linkage pattern of rural roads in hilly regions". JUNIORSTAV 2013, 15th international conference of postgraduate students, Brno University, Czech Republic.

16. Shrestha, J. K., Benta, A., Lopes, R. B., Lopes, N., Ferreira, C. (2012). "A numerical model for rural road network optimization in hilly terrains". First ECCOMAS Young Investigators Conference (YIC2012), University of Aveiro, Portugal.

17. Singh, A.K. (2010). "GIS Based Rural Road Network Planning for Developing Countries." Journal of Transportation Engineering doi:http://dx.doi.org/10.1061/(ASCE)TE.19435436.0000212

18. Tech Studio of Engineering (2011). "Preparation of Detailed Project Report of Mid Hill Highway Project", Department of Roads, Ministry of Physical Planning, Government of Nepal. 